\title{
Geotechnical Characterization of Sakakini’s Palace Stones and Other Construction Materials, Cairo-Egypt
}

\author{
Sayed Hemeda \\ Conservation Department, Faculty of Archaeology, Cairo University, Cairo, Egypt \\ Email: hemeda@civil.auth.gr
}

Received September 9, 2012; revised October 26, 2012; accepted November 29, 2012

\begin{abstract}
The understanding of the geotechnical problems and failure mechanisms of stone structures of Sakakini palace (1897 after century) entails a comprehensive study on the mechanical behaviour of the stones and other construction materials. In addition to micro analysis, geological and geomorphologic interests, several investigations on stone deterioration and engineering geology were performed. First phase included more sophisticated techniques, which provided additional information on particular aspects of site deterioration and it included laser induced breakdown spectroscopy (LIBs), electron probe micro analysis, micro XRD and XRF analyses, scanning electron microscope analysis coupled with EDX probing, transmission electron microscopy and grain size distribution analysis, permeability and pore size distribution of stone, mortars, core binders and other construction materials. Second phase included the determination of mechanical properties of building stones, such as compressive strength, modulus of elasticity, tensile strength, and shear strength. To arrive at reliable values for these properties, a suitable number of samples should be extracted, prepared for testing, and properly tested. The test results are then analyzed to establish the investigated stone properties. The testing program includes extracting seven cylindrical cores from the basement stone walls of Sakakini's mansion in down town Cairo. The cores are extracted using rotary cylindrical diamond blade coring machine. The top and bottom surfaces of every core were prepared to be flat circular surfaces perpendicular to the vertical axis of the core. Because the palace is museum and attractive places for the tourists, core sampling could be carried out only at a limited number of locations under official permission. For the purpose, cylindrical specimens with a diameter of $42-44 \mathrm{~mm}$ and height of $90-100$ $\mathrm{mm}$, prepared by the use of a core drilling machine and some collected blocks from the archaeological site under investigation were taken to determine the bulk structure, physical, short and long-term mechanical properties of the stone and other construction materials in the laboratory. A number of specimens prepared from these blocks were employed for testing. Furthermore, limitation due to the number of blocks was overcome by the determination of the in situ characteristics of the stones by Schmidt hammer tests, geo-tomographic investigations and rock mass classification on some stone rock structures where testing has been permitted. The objectives of the study are to provide a characterization of micro structures and the mechanical properties of the stones of Sakakini's Mansion; describe the required testing plan; describe the test results and conclude the values of the basic mechanical properties of the building stones. The following sections provide detailed descriptions of the steps taken to achieve the objectives of the study. The purpose of the present research is to provide recommendations regarding the strengthening and the safety of architectural heritage under long and short-term loading. For this purpose, a set of experimental tests and of advanced numerical analyses are to be carried out.
\end{abstract}

Keywords: Architectural Heritage; Sakakini Palace; Geotechnical; Investigations; Mechanical Properties; Stone Deterioration; Laser Induced Breakdown Spectroscopy (LIBS)

\section{Introduction}

The site of Habib Sakakini's palace is considered from the important sites that have attracted the attention of a lot of historicans, especially at the Mamluk's and Ottoman's era. The location of that palace anciently was a water pond that was located at the eastern side of Egyptian gulf besiding Sultan Bebris Al-Bondoqdary mosque as that pond was so called "Prince Qraja al-Turkumany pond". That pond had acquired the extent of importance when it had been filled down by Habib Sakakini at 1892 After Century, where he had constructed his famous palace in 1897 AC, Figure 1.

Chalky stones and the other kind of construction materials (which are under investigation) are porous rocks with complex behaviour, two main deformation mechanisms can be commonly identified in theses rock types, depending on the applied stress conditions: 1) fracture 
propagation, associated with volumetric dilatancy and brittle behaviour, which is dominant in compressive stress paths at no or low confining pressure; 2) pore collapse, which dominates at higher stress conditions, producing large contracting plastic deformations.

The high fossils content, due mainly to shells of foraminifers and some mollusks, give rise to structural heterogeneity, which reflected in the variability of the mechanical properties and in the poor reproducibility of the experimental results [1,2].

There is no generally accepted theory of strength of brittle rock based on an examination of process of formation of micro cracks and deformation (Maizel.I.V and Sokolov.I.B), and establishing the initiation and development of stress-induced microfractures in the (EDZ) is thus of key interest.

Some of the key concerns regarding the stability of monumental structures of soft rocks, include the implications of potential ground disturbance by the constrction method and the redistribution of in situ stresses. Both of these factors relate to the initiation and propagation of brittle fractures and the extent of the excavation-disturbed zone (EDZ), which could adversely affect the stability of the stone structures boundary and could increase the permeability of the near-field host rock. In structural Geology and Tectonics, experimental rock deformation is important in determining the evolution of natural structures and tectonic features.
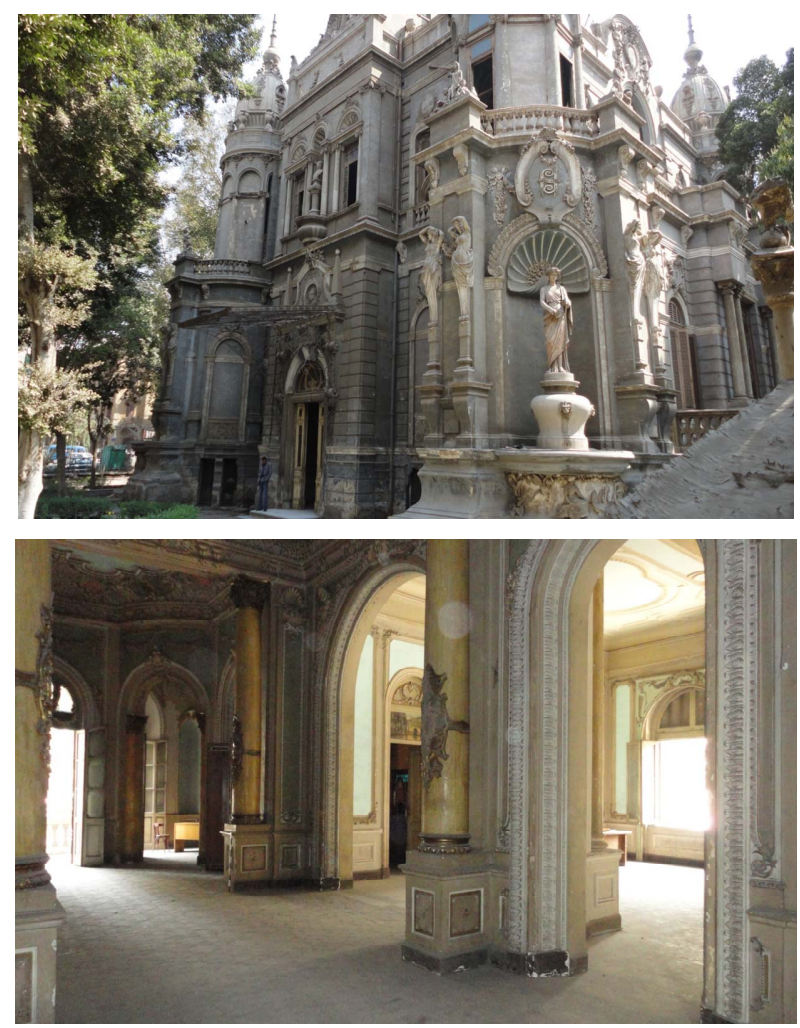

Figure 1. Sakakini palace in Cairo, Egypt.
Considerable effort has been extended towards the understanding of brittle fracture processes and mechanisms. Much of this focus has been extended to laboratory testing and the measurement/quantification of brittle fracture thresholds [3-7]. Of these the crack damage threshold (marked by the onset of dilatancy and taken as the point of reversal in the volumetric strain curve is of specific interest as several studies have associated the threshold with unstable crack propagation in brittle rocks [8]. unstable crack propagation corresponds to the point where the relationship between the applied stress and the crack growth velocity, take control of the propagation process. Under such conditions crack propagation will continue until failure even if the applied loading is stopped and held constant. As such, martin \& chandler and read et al. [9] have equated the crack damage threshold to the long-term in situ strength of brittle rock, a practice they note that has been similarly adopted in the concrete industry.

Thus, the identification of these processes and their associated mechanisms are of key interest in predicting both the short and long-term strength of soft rock. This research focuses on these processes by presenting the results from several short and long-term laboratory tests.

In general, the propagation of a brittle fracture can be equated with the irreversible destruction of molecular cohesion along the generated fracture path. In this sense, the microfracturing process acts to "damage" the rock material. As the number of propagating fractures multiplies, damage can be viewed as accumulative and can be correlated to observed decreases in the elastic stiffness and cohesive strength of the material.

In this work, we highlighted some important characteristics of the geotechnical behaviour of structured soft rock and showed that these characteristics are quite common in many natural rocks. Based on such concepts, research into soft rock materials has intensified in the last two decades [10].

\section{Bulk Structure and Durability Aspects of Stone, Mortars and Core Binders}

Various techniques were used to establish the causes of the stone deterioration in Sakakini palace. The first group of techniques was used to establish site parameters and it included photographic recording, petrographic analysis of the stone type, microclimate data, ground water composition and ultra violet radiation levels.

The second group included more sophisticated techniques, which provided additional information on particular aspects of site deterioration and it included laser analysis (LIBS) [11,12], electron probe micro analysis, micro XRD, Table 1 and XRF, Table 2 analyses, scanning electron microscope analysis coupled with EDX probing, transmission electron microscopy and grain size 
Table 1. XRD analysis results for stone and other construction materials.

\begin{tabular}{cccc}
\hline S. No. & $\begin{array}{c}\text { Major } \\
\text { Const }\end{array}$ & Minor Const & $\begin{array}{c}\text { Trace } \\
\text { Const }\end{array}$ \\
\hline $\begin{array}{c}\text { Chalky limestone } \\
\text { Mortars between } \\
\text { stone blocks }\end{array}$ & Calcite & - & Calcite \\
$\begin{array}{c}\text { Render or plaster } \\
\text { layers }\end{array}$ & $\begin{array}{c}\text { Quartz, } \\
\text { Halite, } \\
\text { Gypsum }\end{array}$ & Calcite & Gypsum \\
$\begin{array}{c}\text { Core binders } \\
\text { between leave } \\
\text { masonry walls }\end{array}$ & Quartz & Calcite & Calcite \\
\hline
\end{tabular}

Table 2. XRF analysis results for stone and other construction materials.

\begin{tabular}{ccccc}
\hline $\mathrm{D} . \mathrm{N}$ & $\begin{array}{c}\text { Chalky } \\
\text { Limestone }\end{array}$ & $\begin{array}{c}\text { Mortars } \\
\text { between } \\
\text { stone blocks }\end{array}$ & $\begin{array}{c}\text { Render or } \\
\text { Plaster } \\
\text { layers }\end{array}$ & $\begin{array}{c}\text { Core Binders } \\
\text { between leave } \\
\text { masonry walls }\end{array}$ \\
\hline $\mathrm{SiO}_{2}$ & 0.81 & 63.28 & 30.18 & 65.28 \\
$\mathrm{TiO}_{2}$ & 0.05 & 0.25 & 0.06 & 0.55 \\
$\mathrm{Al}_{2} \mathrm{O}_{3}$ & 1.13 & 3.9 & 0.63 & 7.27 \\
$\mathrm{Fe}_{2} \mathrm{O}_{3}$ & 0.17 & 1.65 & 0.28 & 3.48 \\
$\mathrm{MnO}$ & 0.002 & 0.02 & 0.003 & 0.05 \\
$\mathrm{MgO}^{2}$ & 1.01 & 1.17 & 0.9 & 1.28 \\
$\mathrm{CaO}^{2}$ & 52.5 & 14.08 & 10.28 & 11.13 \\
$\mathrm{Na}_{2} \mathrm{O}$ & 0.12 & 0.81 & 12.01 & 0.87 \\
$\mathrm{~K}_{2} \mathrm{O}$ & 0.15 & 0.73 & 1.94 & 0.88 \\
$\mathrm{P}_{2} \mathrm{O}_{5}$ & 0.1 & 0.13 & 0.09 & 0.19 \\
$\mathrm{Cl}$ & 0.24 & 0.65 & 12.07 & 0.94 \\
$\mathrm{SO}_{3}$ & 0.9 & 1.85 & 11.34 & 1.76 \\
$\mathrm{~L} . \mathrm{O} . \mathrm{I}$ & 42.45 & 10.83 & 20.1 & 5.97 \\
\hline & & & & \\
\hline
\end{tabular}

distribution analysis of rock samples, permeability and pore size distribution of stone, mortars and core binders.

\subsection{Chalky Limestone}

The limestone can be characterized as medium grained with uniform relative grain size, angular to sub angular grain shape with equidimensional form and rough surface texture. Sound or non weathered pieces of stone can be characterized of medium compactness and durability and the weathered pieces characterized of low compactness and durability. It must be mentioned that weathering attacked strongly the masonry units, started from the sur- face and continuing inward thus loosing the mineral fabric, Figure 2.

LIBS spectrum, Figure 2, and The EDX micro analyses indicated that, the elemental arrangement for the chalky limestone samples collected from Sakakini place can be put in a decreasing order according to their concentration as follow:

$\mathrm{Ca}(33.50 \%), \mathrm{O}(29.80 \%), \mathrm{S}(16.94 \%), \mathrm{K}(9.01 \%), \mathrm{C}$ (6.53\%), Fe (1.76\%), Si (1.48\%), $\mathrm{Al}(0.55 \%), \mathrm{Mg}(0.44 \%)$. Total $100.00 \%$ (wt $\%)$. see Figure 3.

\subsection{Mortars between Stone Blocks}

Mortars between stone blocks are coarse to very fine grained, compact, and poorly sorted. It composed of quartz as the essential mineral constituents with rare amounts of rock fragments, hornblende, collophane, epidote, gluconite and opaques all cemented by very fine grained calcite (micrite) admixed with traces of iron oxides and clay materials. Quartz occurs as coarse to finegrains of rounded to subangular outlines, and some quartz grains are polycrystalline. Feldspars and rock fragments detected in the rock as coarse to medium grains.

LIBS spectrum and The EDX micro analyses indicated that, the elemental arrangement for the Mortars between stone blocks samples collected from Sakakini place can be put in a decreasing order according to their concentration as follow:

$\mathrm{Ca}(49.21 \%), \mathrm{O}(32.70 \%), \mathrm{Si}(6.77 \%), \mathrm{C}(5.85 \%), \mathrm{Fe}$ (2.25\%), $\mathrm{Al}(2.25 \%), \mathrm{K}(0.67 \%)$. Total $100.00 \%$ (wt\%).

\subsection{Plaster or Render Layers}

The renders layers are medium to fine-grained, compact. The renders composed mainly of quartz, Gypsum with rare amounts of feldspars, clay minerals and iron oxides. Quartz occurs as medium to fine-grains of rounded to subangular outlines, and some quartz grains are polycrystalline. The matrix is composed of a mixture of micrite with minor amount of clay minerals and iron oxides.

The grade of disintegration and deterioration usually goes with the salt content, it was found that pollutants from car traffic, attack mortars as well as chlorines from the ground water, lower parts covered for long time with ground also present high percentage in $\mathrm{NaCl}$ and $\mathrm{NO}$ and $\mathrm{SO}_{4}$ salts.

LIBS spectrum and The EDX micro analyses indicated that, the elemental arrangement for the renders layers samples collected from Sakakini place can be put in a decreasing order according to their concentration as follow:

O (37.50\%), Si (26.60\%), C (11.72\%), Ca (10.42\%), S (9.52\%), $\mathrm{Mg}(1.23 \%), \mathrm{Na}(1.21 \%), \mathrm{Cl}(1.1 \%), \mathrm{Al}(0.71 \%)$. Total $100.00 \%$ (wt $\%$ ). 

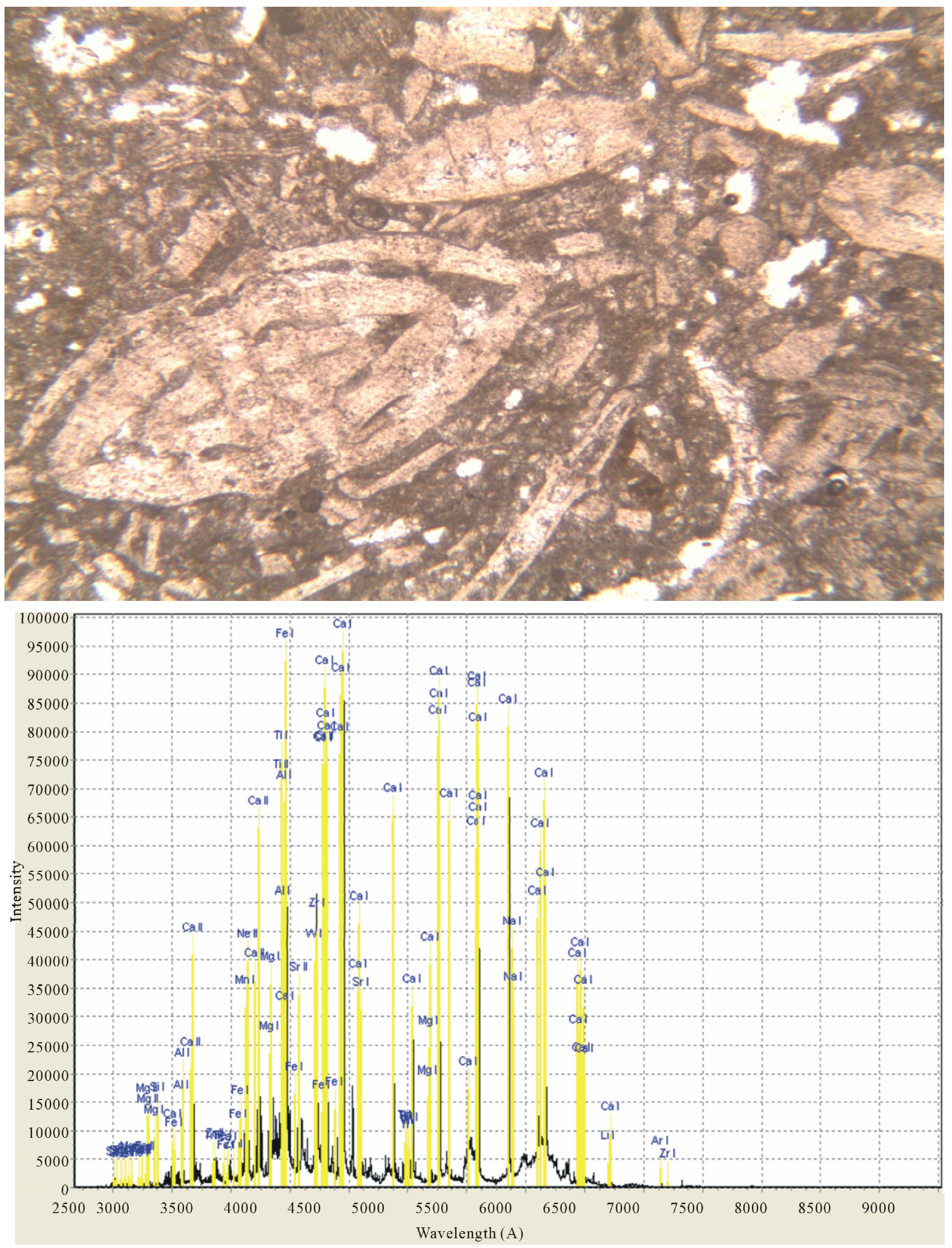

Figure 2. Thin section and Libs spectrum for an analysis spot on building limestone. 

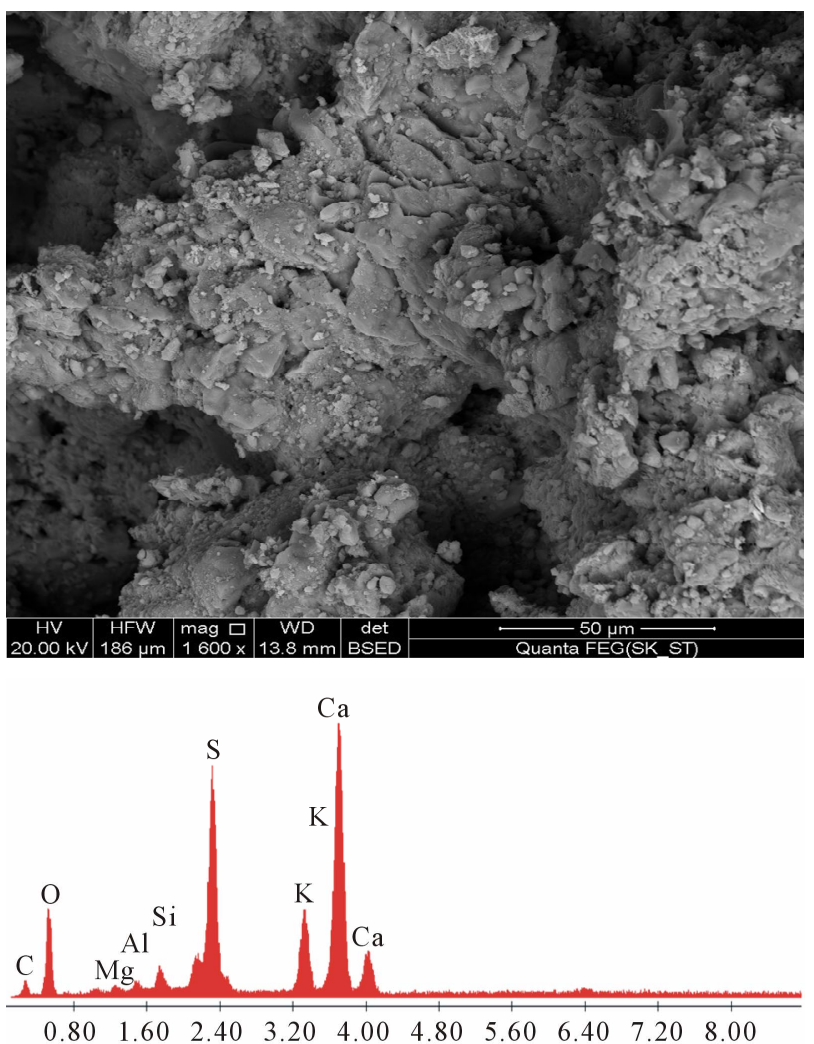

Figure 3. SEM with EDX analysis results of chalky limestone.

\subsection{Core Binders between Leave Masonry Walls}

The core binders between two leaves are coarse to veryfine grained compact. It composed of quartz as the essential mineral constituents-with minor amount of feldspar and rare amounts of rock, stone and brick fragments, collophane, glauconite and opaques all cemented by very fine grained calcite (micrite) admixed with traces of iron oxides and clay materials. Quartz occurs as coarse to fine-grains of rounded to subangular outlines, and some quartz grains are polycrystalline. Feldspars and rock fragments detected in the rock as coarse to medium grained.

The grade of disintegration and deterioration usually goes with the salt content. Although the research was not oriented to estimate the grade of deterioration, it was found that pollutants from car traffic, attack mortars as well as chlorines from the ground water, lower parts covered for long time with ground also present high percentage in $\mathrm{NaCl}$ and $\mathrm{Na}_{2} \mathrm{SO}_{4}$ salts.

LIBS spectrum and The EDX micro analyses indicated that, the elemental arrangement for the Core binders between leave masonry walls samples collected from Sakakini place can be put in a decreasing order according to their concentration as follow:

Ca (39.29\%), O (29.44\%), Si (17.13\%), C (5.17\%), Al
(4.73\%), Fe (3.16\%), S (9.52\%), Cl (0.58\%), $\mathrm{Mg}(0.49 \%)$. Total $100.00 \%(\mathrm{Wt} \%)$.

\section{Mechanical Testing Program}

The basic mechanical properties of building stones are compressive strength, modulus of elasticity, tensile strength, and shear strength. To arrive at reliable values for these properties, a suitable number of samples should be extracted, prepared for testing, and properly tested. The test results are then analyzed to establish the investtigated stone properties.

The testing program includes extracting seven cylindrical cores from the basement stone walls of Sakakini's mansion in down town Cairo. Figure 4 The cores are extracted using rotary cylindrical diamond blade coring machine. The top and bottom surfaces of every core were prepared to be flat circular surfaces perpendicular to the vertical axis of the core, Figure 5.

Three cores were equipped with strain gauges to measure the longitudinal strain corresponding to compressive stresses. The results of testing these three cores in compression will be used to determine the stones compressive strength and modulus of elasticity.

Three cores were tested in splitting tension to determine the tensile strength of the stone samples. One core was tested in single shear to determine the stone's shear strength.

The following sections describe the different tests and discuss their results.
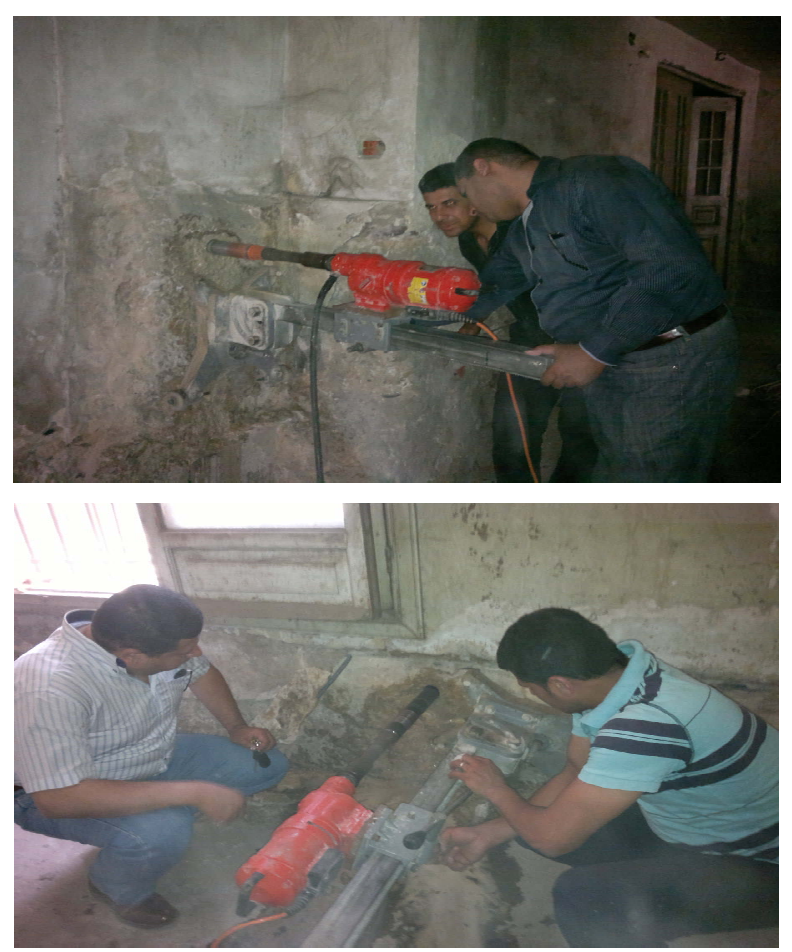

Figure 4. Core samples extracting from the basement. 


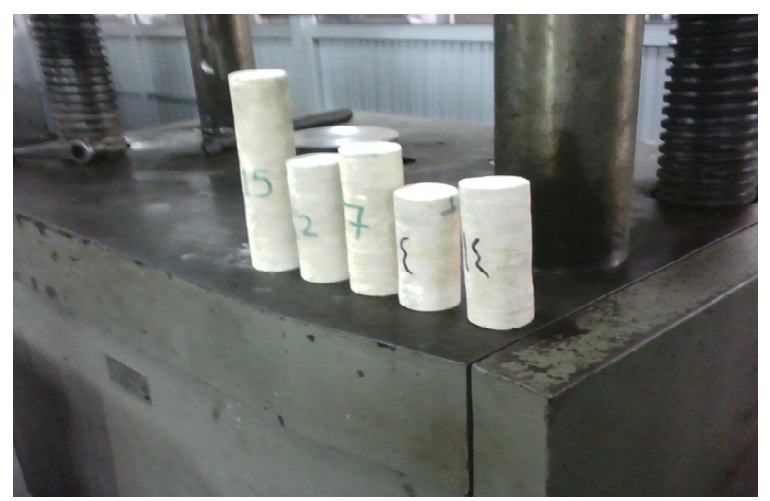

Figure 5. Some core samples after preparation.

\subsection{Compressive Strength}

Three samples were equipped with $100 \mathrm{~mm}$ long electric strain gauges. One strain gauge was fixed to the core parallel to its vertical axis to measure the longitudinal compressive strain corresponding to the applied compressive stress, Figure 6. The vertical compressive stress was increased gradually until failure. The compressive strength of every core was determined. Table $\mathbf{3}$ shows the results of the compressive strength of the three cores, Figures 7 and 8.

\subsection{Modulus of Elasticity}

The recorded stress-strain data for the three samples are graphed as shown in Figures 9-11. From these figures, the value of the modulus of Elasticity can be obtained. For brittle materials with non-linear stress-strain relationship; the modulus of elasticity may be determined as the chord modulus between a low stress value $(0.5 \mathrm{MPa})$ and a stress value equals one third of the compressive strength. For such definition the values of the modulus of elasticity obtained for the three tested samples are given in Table 4.

\subsection{Splitting Tensile Strength}

Three samples were tested to determine the average splitting tensile strength of the stone. Figure 12 shows a sample in the test set-up at failure. Table 5 gives the details of the test results.

\subsection{Shear Strength}

One sample was tested in single shear to determine the shear strength of the stone. The obtained shear strength equals $1.63 \mathrm{MPa}$.

\subsection{Abrasion Test}

Results from the abrasion test on some white Karara Marble specimens indicated that, the loss of weight is about 7-8 g, and loss of thickness is $0.66 \mathrm{~mm}$, Table 6 .

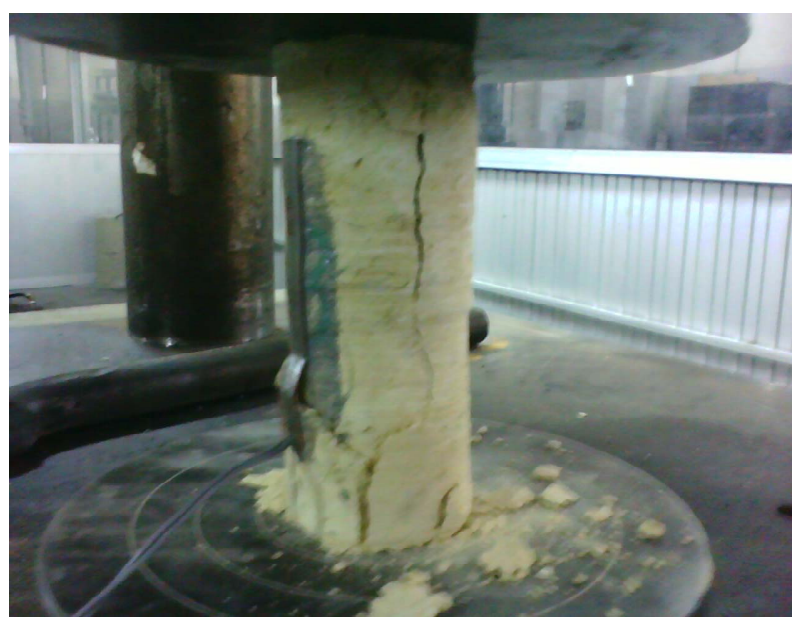

Figure 6. Test set-up.

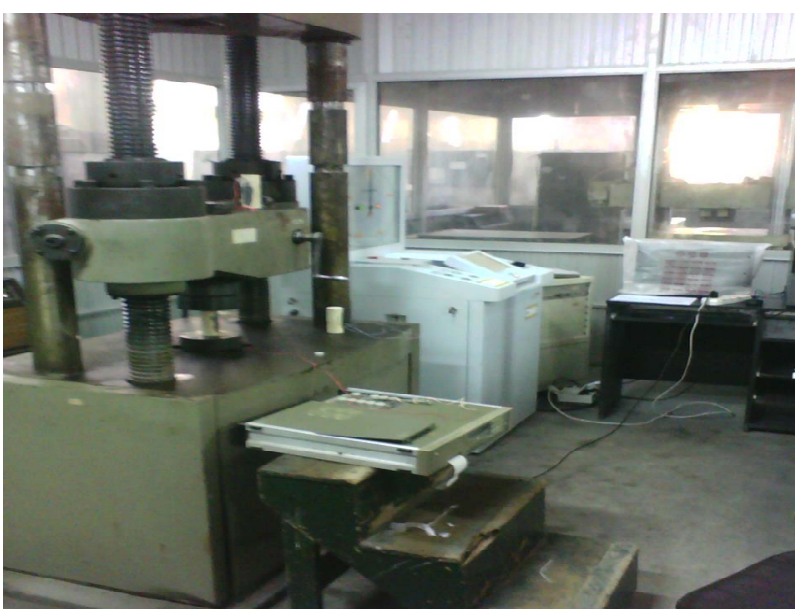

Figure 7. Compressive strength sample at failure.

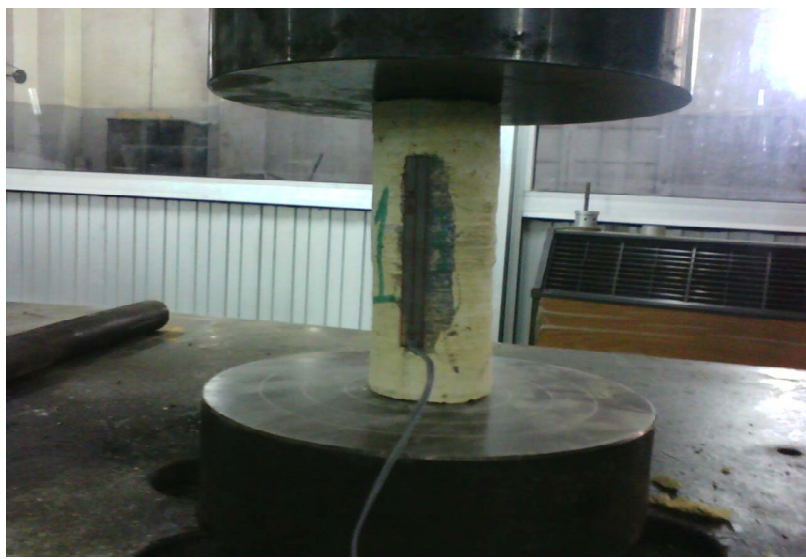

Figure 8. Compressive strength sample in the test set-up.

\subsection{Bending Moment}

Bending moment test on some Boghdadi blocks wooden specimens had been carried out and the results indicated that the bending moment value ranging between 379 and $592 \mathrm{~kg} / \mathrm{cm}^{3}$, Table 7 . 
Table 3. Compressive strength test results.

\begin{tabular}{|c|c|c|c|c|c|c|}
\hline No. & Diam. (mm) & Height (mm) & Cross Sectional Area $\left(\mathrm{mm}^{2}\right)$ & Failure Load (kN) & Compressive Strength (MPa) & Remarks \\
\hline 1 & 44.7 & 132 & 1569.3 & 16.50 & 10.5 & - \\
\hline 2 & 42.7 & 117 & 1432.0 & 14.90 & 10.4 & - \\
\hline 3 & 44.1 & 136 & 1527.5 & 16.22 & 10.6 & - \\
\hline 4 & 49.1 & 140 & 1886.3 & 17.80 & 9.44 & - \\
\hline 5 & 49.1 & 161 & 1886.2 & 22.90 & 12.14 & - \\
\hline 6 & 49.1 & 168 & 1886.2 & 13.30 & 7.05 & - \\
\hline 7 & 49.1 & 200 & 1886.2 & 15.70 & 8.32 & - \\
\hline
\end{tabular}

Table 4. Modulus of elasticity for the stone samples.

\begin{tabular}{cccccc}
\hline No. $\begin{array}{c}\text { Strain at } 0.5 \\
\mathrm{MPa}\left(\times 10^{-6}\right)\end{array}$ & $\begin{array}{c}\text { Ultimate } \\
\text { Strength } f_{\text {ult }} \\
(\mathrm{MPa})\end{array}$ & $\begin{array}{c}\text { Strain at } \\
\mathrm{fult}_{\text {ult }} / 3\left(\times 10^{-6}\right)\end{array}$ & $\begin{array}{c}\text { Modulus of } \\
\text { Elasticity } \\
(\mathrm{GPa})\end{array}$ & Remarks \\
\hline 1 & 10 & 10.5 & 301 & 17.182 & - \\
2 & 13 & 10.4 & 213 & 22.500 & - \\
3 & 4 & 10.6 & 250 & 18.293 & - \\
\hline
\end{tabular}

Table 5. Splitting tensile test results.

\begin{tabular}{cccccc}
\hline & & & & \multicolumn{2}{c}{ Splitting } \\
No. & $\begin{array}{c}\text { Diam. } \\
(\mathrm{mm})\end{array}$ & $\begin{array}{c}\text { Height } \\
(\mathrm{mm})\end{array}$ & $\begin{array}{c}\text { Ultimate Load } \\
(\mathrm{kN})\end{array}$ & $\begin{array}{c}\text { Tensile Strength Remarks } \\
(\mathrm{MPa})\end{array}$ & \\
\hline 1 & 44 & 101 & 10.35 & 1.48 & - \\
2 & 44 & 117 & 15.02 & 1.86 & - \\
3 & 44 & 117 & 12.07 & 1.49 & - \\
4 & 49 & 12.2 & 10.90 & 1.16 & - \\
5 & 49 & 11.0 & 15.00 & 1.77 & - \\
6 & 49 & 13.6 & 11.70 & 1.12 & - \\
7 & 49 & 13.2 & 13.57 & 1.34 & - \\
\hline
\end{tabular}

\subsection{Physical Properties}

Generally speaking, it could be said that although high absorption means low strength there are some exceptions. Where we have high absorption we have high strength and of course, for the same strength a high range of absorption. Helped by the record card data bank files, these peculiarities can be explained. High content in clay or argillaceous materials increase absorption. This obvious in microscopic analysis.

When cracks are present in the mass of the building stones the absorption is over $0.6 \%$ Table 8. For the sound stone samples absorption ranges from $0.4 \%$ to $0.5 \%$. For $50 \%$ of the samples absorption is below $0.5 \%$.
Table 6. Abrasion Test Results of Marble specimens.

\begin{tabular}{ccccc}
\hline No. & $\begin{array}{c}\text { Dry Weight } \\
(\mathrm{gr})\end{array}$ & $\begin{array}{c}\text { Loss of Weight } \\
(\mathrm{gr})\end{array}$ & $\begin{array}{c}\text { Loss of Thickness } \\
(\mathrm{mm})\end{array}$ & Remarks \\
\hline 1 & 211 & 7 & 0.66 & $\begin{array}{c}\text { White } \\
\text { Karara }\end{array}$ \\
2 & 213 & 7 & 0.56 & - \\
3 & 215 & 8 & 0.70 & - \\
\hline
\end{tabular}

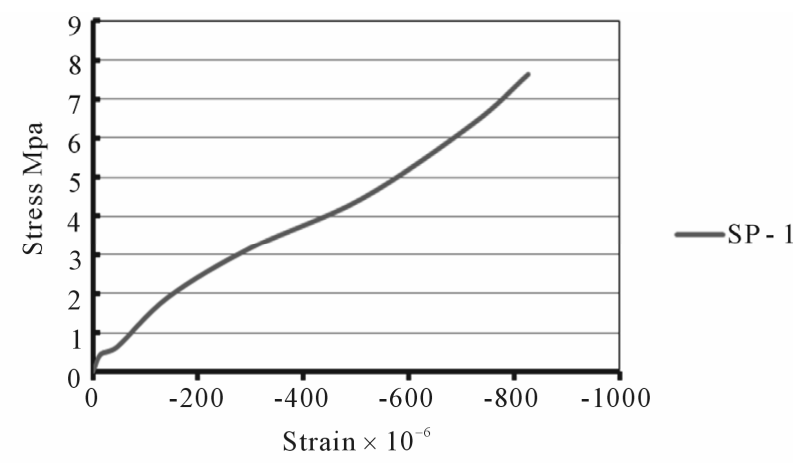

Figure 9. Stress-strain curve for sample 1.

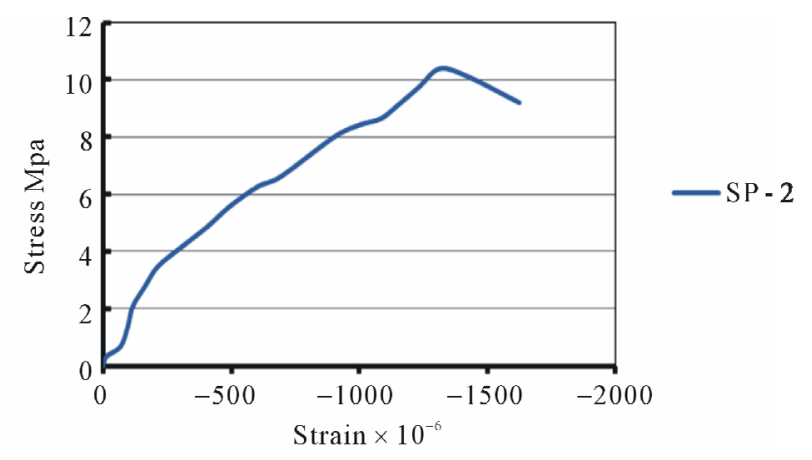

Figure 10. Stress-strain curve for sample 2.

For the $65 \%$ of the samples the apparent specific gravity ranges from 1.8 to $2 \mathrm{gr} / \mathrm{cm}^{3}$. 


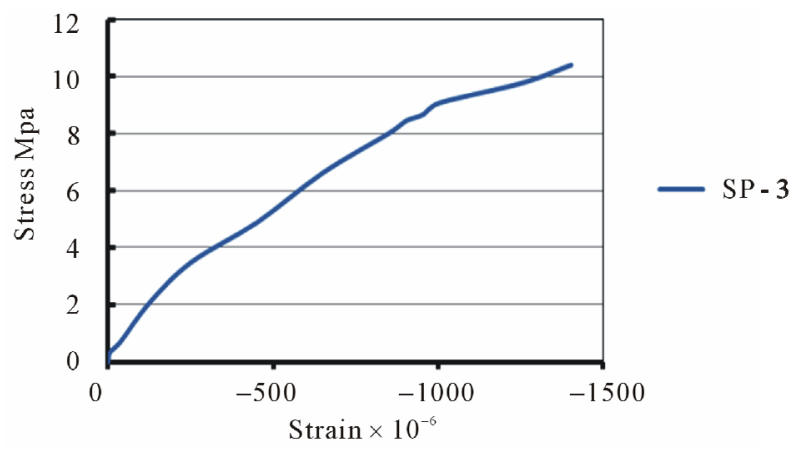

Figure 11. Stress-strain curve for sample 3.

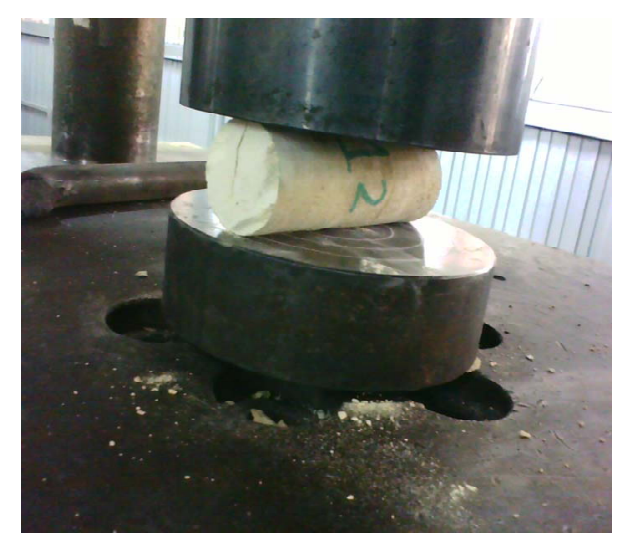

Figure 12. Splitting tensile test sample at failure.

Table 7. Bending moment test results of wooden specimens.

\begin{tabular}{cccccc}
\hline No. & $\begin{array}{c}\text { Dimensions } \\
(\mathrm{mm})\end{array}$ & $\begin{array}{c}\text { Span } \\
(\mathrm{mm})\end{array}$ & $\begin{array}{c}\text { Ultimate } \\
\text { load }(\mathrm{kg})\end{array}$ & $\begin{array}{c}\text { Bending moment } \\
\left(\mathrm{kg} / \mathrm{cm}^{2}\right)\end{array}$ & Remarks \\
\hline 1 & $94 \times 31$ & 20 & 1140 & 379 & Block \\
2 & $30 \times 13$ & 20 & 100 & 591.7 & Boghdadi \\
3 & $30 \times 13$ & 20 & 100 & 592 & - \\
\hline
\end{tabular}

Table 8. Physical properties of marble specimens.

\begin{tabular}{ccccc}
\hline No. & $\begin{array}{c}\text { Dry weight } \\
(\mathrm{gr})\end{array}$ & $\begin{array}{c}\text { Saturated } \\
\text { weight (gr) }\end{array}$ & $\begin{array}{c}\text { absorption } \\
(\%)\end{array}$ & Remarks \\
\hline 1 & 124 & 124.5 & 0.4 & $\begin{array}{c}\text { White } \\
\text { Karara }\end{array}$ \\
2 & 124 & 125 & 0.4 & - \\
3 & 124 & 125 & 0.5 & - \\
\hline
\end{tabular}

\section{Pathology Assessment and Causes of Deterioration}

The structure of the vast complex of the palace is unusually complicated. These buildings are of non-homogenous structural features, their elements are made of different construction materials and its foundations are of various levels and configurations.

An inspection of the palace revealed that while the de- terioration seems to be geotechnical, seismic and moisture/weathering problems, other instances of deteriorations are caused by structural systems of the buildings. The structural system is a largely to be regarded as a free shear-wall system, in which the load-bearing walls are neither always placed on top of each other nor upon strong beams transmitting their load to other continuous structural components.

The foundations were found to be built on different levels. Under a certain wall, the footing was found to be partly supported on the remains of the underground structure while the other parts are in the fill layer. The foundations in some locations were not found. Visual cracks were observed to verify that the foundations of the building had been subjected to differential settlements.

The stability problems of these structures are mainly related to the damage caused by the earthquake \& seismic and geotechnical hazards also the foundation subsidence and deformations and fractures on the walls, as well as the weathering of stones and others construction materials by ground water, polluted atmosphere, temperature variations and the mechanical action of wind, where historical building stones exposed to atmospheric factors are subject to the action of various agents causing their destruction. A complex combination of mechanical, chemical, biological factors played an important role in the deterioration of the building stones of palace.

Type of damage recognized:

1) Flakes or scaling at the surface;

2) Loss of mass;

3) Changes in shape (worn rectangular angles);

4) Efflorescence;

5) Changing in colour (smoked brick);

6) Presence of fungus;

7) Pulverization.

The symptoms of building stones disintegration usually go in parallel with the high humidity of the walls. Salts are often concentrated in the voids without cracking around them. In many cases recrystallization takes place in the cracks which constitute the veneers of liquid faces. Salt crystals are usually in microcrystalic form and rarely in well developed crystal shape. It seems that the high content in salts has a detrimental effect on stone strength.

The process of the mechanical deterioration affecting the structures are abrasion, polishing, scouring, scratching splitting, cracking fragmentation and stone fall. These processes are reflected by striations, polished surfaces, undulating surfaces, cracks, fissures and joints and finally rock loose. Water/salt combination activated by fluid circulation and evapo-transpiration, is one of the main factors which provoke weathering and decomposition of a stone, by reaction of shrinking-expansion phenomena of pore water.

We can see decays by supply of matter such as brown crust, damages by loss of matter such as dissolution, 
other degradations by loss of matter such as granular disintegration and contour scaling (on parts exposed to rains), the presence of salts leads to dissolution and crystallization cycles of salts, especially inside the porous network, this mechanism occurs: 1) by capillary transfer of water and salt from the ground and 2) by fixation of water vapor by sea salt deposited on the stone by the wind. And the action of plant's root in a particularly porosity material of construction.

The role of human activities is very dangerous in which the building stone were subjected to scratch, breaking down or removing and reuse of stones.

\section{Conclusion}

A testing program was planned and executed to determine the basic structure/composition and mechanical properties of Sakakini's Mansion Building Stones. Micro structure analysis, the compressive strength, Modulus of Elasticity, Splitting tensile Strength and Shear Strength were determined as shown in the previous sections of this report.

\section{Acknowledgements}

The present paper is part of project entitled "risk assessment and seismic response analysis of architectural heritage in Egypt" funded by Cairo University and under the management of Dr Sayed Hemeda, the author of the paper and main investigator of the project. I gratefully acknowledge the support and assistance of Professor Osama A. Hodhod, professor of strength of materials, Structural Engineering Department, Faculty of Engineering, Cairo University for his great efforts and help through the investigations, while the mechanical testing had been carried out in the laboratory of (CERC) Civil Engineering Research Centre, Cairo University under request and supervision of Dr Sayed Hemeda.

\section{REFERENCES}

[1] Z. S. Bieniawski, "The Geomechanics Classification in Rock Engineering Applications," 4th ISRM Congress, In- ternational Society for Rock Mechanics, Switzerland, 1979, pp. 41-48.

[2] M. Bukovansky, D. P. Richard and K. R. Week, "Influence of Slope Deformations on the Tombs in the Valley of the Kings, Egypt," Proceedings of an International Symposium on Engineering Geology and the Environment, Vol. 3, 1997, pp. 3077-3080.

[3] D. U. Deere and O. A. Varde, "General Report, Engineering Geological Problems Related to Foundations and Excavations in Weak Rocks," Proceedings of the 5th International Association of Engineering Geology Congress, Vol. 4,1990, pp. 2503-2518.

[4] A. De Meer and C. J. Spiers, "Creep of Wet Gypsum Aggregates under Hydrostatic Loading Conditions," Tectonophysics, Vol. 245, No. 3-4, 1995, pp. 171-183. doi:10.1016/0040-1951(94)00233-Y

[5] A. De Meer and C. J. Spiers, "Uniaxial Compaction of Wet Gypsum Aggregates," Journal of Geophysical Research, Vol. 102, No. B1, 1997, pp. 875-891. doi:10.1029/96JB02481

[6] M. Cecconi and G. Viggiani, "Physical and Structural Properties of a Pyroclastic Soft Rock," In: Evangelista and Picarelli, Eds., Proceedings of the Geotechnics of Hard Soils-Soft Rocks, Rotterdam, 1998, pp. 2320-2331.

[7] M. R. Cooper, "The Mechanics of Uncemented Carbonate Sands," Geotechnique, Vol. 40, No. 4, 1990, pp. 607-627.

[8] L. S. Costin, "Time-Dependent Deformation and Failure," In: B. K. Atkinson, Ed., Fracture Mechanics of Rock, San Diego, 1987, pp. 167-215.

[9] S. Hemeda, K. Pitilakis, S. Bandis, I. Papayianni and M. Gamal, "The Underground Monuments (Catacombs) in Alexandria, Egypt," Proceedings of the 4th International Conference on Earthquake Geotechnical Engineering, Thessaloniki, 25-27 June 2007, pp. 715-738.

[10] S. Hemeda, "An Integrated Approach for the Pathology Assessment and Protection of Underground Monuments in Seismic Regions. Application on some Greek-Roman Monuments in Alexandria, Egypt," Ph.D. Thesis, Aristotle University of Thessaloniki, Thessaloniki, 2008.

[11] C. Cennini, "Il libro dell'arte," Neri Pozza, ISBN: 88730591041, 2003.

[12] D. L. Massart, B. G. M. Vandeginste, S. N. Deming, Y. Michotte and L. Kaufman, "Chemometrics: A Textbook," Elsevier Science Publishers, Amsterdam, 1988. 